Reviews in Digital Humanities • Vol. 2, No. 1

\title{
Review: Documenting \\ Judeo-Spanish
}

David M. Bunis 1

${ }^{\mathbf{1}_{H}}$ hebrew University of Jerusalem

Published on: Jan 04, 2021

DOI: $10.21428 / 3 e 88 f 64 f .855 b 4254$

License: Creative Commons Attribution 4.0 International License (CC-BY 4.0). 


\section{Project}

Documenting Judeo-Spanish

\section{Project Director}

Bryan Kirschen, Binghamton University

\section{Project URL}

https://documentingjudeospanish.com/

\section{Project Reviewer}

David M. Bunis, Hebrew University of Jerusalem

\section{Project Overview}

\section{Bryan Kirschen}

Documenting Judeo-Spanish is a digital humanities project that launched in Spring 2020 under the direction of Bryan Kirschen, assistant professor of Spanish and Linguistics at Binghamton University. This project centers on the nearly-extinct cursive Solitreo alphabet, which Sephardic Jews once used for the endangered Judeo-Spanish (Ladino) language. Speakers and scholars of Judeo-Spanish are often unable to decipher content in this Hebrew-based, right-to-left, aljamiado writing system, as the use of Latin characters has all but replaced this centuries-old practice among speech communities worldwide.

The first phase of this project sought to collect, digitize, transcribe, and translate documents in Judeo-Spanish written in Solitreo characters. In reaching out to communities of speakers and archives around the world, Kirschen located over 150 unique documents in this cursive script and obtained necessary permissions and scans for a variety of content in Solitreo, ranging from journal entries and ledgers to personal correspondence and community minutes. Kirschen collaborated with librarians at Binghamton University Libraries on data management, scanning, and metadata, and trained Nathan Gross, an undergraduate research assistant at Binghamton University, to read documents in Solitreo.

The subsequent phase of this project involved creating an online portal featuring a selection of documents in Solitreo. Recognizing the dearth of content available to learn how to read Solitreo, Kirschen decided to implement tools that would allow users to engage with this paleographic endeavor. Documenting Judeo-Spanish utilizes hover- 
over and tooltip features to provide an interactive experience for users exploring the initial 25 documents highlighted on the site. Hovering one's mouse over any word in Solitreo will reveal its Latin-character equivalent form in Judeo-Spanish, while clicking on a word generates a separate tooltip containing the literal translation of the lexical item in question. Below each image, users will find a downloadable PDF file, comprising the parallel text in Romanization of Judeo-Spanish as well as English translation.

This one-of-a-kind platform was created with a diverse audience in mind: educators, students, scholars, and speech communities alike. The site itself offers recommendations to each of the aforementioned audiences for interacting with content. Educators, for example, might wish to introduce their students to a unique variety of Spanish, which developed among Sephardic Jews in places like Turkey, the Balkans, and North Africa, while speakers of this language might use this site and its resources to decipher documents within their families or as a way to reclaim this style of writing.

One area of future development is searchability within and across documents. Allowing users to search for words or phrases in Ladino and having the site generate a list of documents in which these words appear would allow for comparison of variation within a given text as well as across distinct handwritings. Such a feature could also facilitate language learning, especially if the search engine facilitates bidirectional operation (English-Ladino and Ladino-English).

Kirschen was a recipient of the Harpur College Faculty Research Grant, which provided him with support to carry out the initial stages of Documenting JudeoSpanish. He plans to continue expanding this project, both the current interface and selection of documents, as well as additional features. Kirschen and Gross are in the final stages of creating a fully-developed font in Solitreo, which will be available for download on the site. Kirschen is also in the initial stages of creating the first Handwritten Text Recognition program for Solitreo, which will be trained using many of the documents in the collection.

\section{Project Review}

\section{David M. Bunis}

Since the Middle Ages and into modern times the Sephardim - or Jews of Iberia and their descendants in the Ottoman Empire, Austro-Hungary, Italy and other parts of 
Europe, North Africa, and elsewhere - have traditionally used several forms of the Hebrew alphabet to write their traditional language, which is known today by names such as Judezmo, Ladino, and Judeo-Spanish. Square or merubá Hebrew letters were used mostly as a bold face for titles and headings. A formal cursive script and, from the 15th century, a printing font based upon that script, which has come to be known as Rashí letters, was used for formal manuscript writing and for the main portion of most printed texts. A much more highly cursive form of that script, which in the modern era has come to be known as soletreo/solitreo or ḥași qolmos, was used by Judezmo speakers for general manuscript writing of texts in Judezmo as well as Hebrew and Aramaic. Until the 1920s and '30s members of Judezmo-speaking society learned to read and write the varieties of the Hebrew alphabet used for their native language during childhood. But with the transition around that time from the traditional Sephardic to the modern Western European lifestyle, the Hebrew alphabet for writing Judezmo was replaced mostly by the Latin alphabet.

Since the late 19th century, scholars have been taking up the challenge of analyzing surviving traditional Hebrew-letter Judezmo texts, which document the historical development of the language over the course of its long history and throughout its broad speech territory. Because of the relative clarity of their letters and their familiarity to those with knowledge of Hebrew, the Judezmo documents in the Square letters and the formal Rashí manuscript and printed letters have been analyzed by scholars with comparative ease. As a result of Hebrew's use for writing and printing in the State of Israel, where it is the official language, great strides have been made in the digitization technology enabling the optical character recognition of printed Hebrew letters, including the Square and Rashí fonts used in Judezmo printed texts.

There now remains one major obstacle to overcome: the interpretation and optical character recognition of the highly cursive soletreo script used by the Judezmospeaking Sephardim in the thousands upon thousands of extant Judezmo, Hebrew, and Aramaic manuscripts written from the Middle Ages into modern times. This script is entirely unknown to most Judezmo speakers today, and many scholars of the language lack familiarity with it. Further complications in the analysis of the script are its temporal and regional divergences and the tendency toward ligature by which letters are often joined together.

In his project, Documenting Judeo-Spanish, Bryan Kirschen seeks to tackle the Judezmo portion of the soletreo problem. Skillfully using the latest digitization technology and tools of corpus analysis, the project provides site users with an entrée 
into the soletreo script, enabling them to interact with a modest but expanding and diversified corpus of Modern Judezmo texts in soletreo and compare them with Latinletter correspondents and English equivalents. Kirschen and his team have digitized hundreds of pages of content in soletreo, working with communities and institutions to locate and scan material. As this project continues to develop, one of its aims is ultimately to enable a search engine within the site, similar to the current layout of the postcard section. Allowing users to search for words not only in a given document but across documents will facilitate comparative analysis and research among scholars interested in variation of both handwriting, lexicon and, to an extant, even morphosyntax.

It should be noted that by using custom vector shapes to identify the contours and parameters of every word throughout these documents, users are able to decipher the content in both transliteration and transcription. Documenting Judeo-Spanish allows users to hover over any area of text in soletreo, which will subsequently generate a tooltip with the Aki Yerushalayim Latin-character spelling of the word in question. Aside from the hover-over feature, users can click on any word in soletreo to reveal its translation in English. Metadata are also provided at the bottom of each page, and a digital soletreo font is in preparation.

Documenting Judeo-Spanish demonstrates the latest example of innovation in digitization and presentation of this language. As the site indicates, the intended audience of this project includes both those within and outside of academia. While this site will provide users the opportunity to learn the letter-to-letter equivalencies between Judezmo in soletreo and Latin letters, this site also allows visitors - both novices and advanced readers - to practice and keep up their ability to read documents in this Hebrew-based cursive variety.

This praiseworthy project promises to place the once highly esoteric soletreo script and the multitude of Judezmo manuscripts penned in it within the reach of scholars and other Judezmo readers. Given the complexities of the script and its somewhat idiosyncratic use by thousands of individual manuscript writers, the path to success will not be easy, but the project director and his team show every sign of being able to bring the project to a fruitful conclusion. 